\title{
Diversity patterns and chronobiology of hawkmoths (Lepidoptera, Sphingidae) in the Brazilian Amazon rainforest
}

\author{
Amabílio J. A. de Camargo ${ }^{1}$ Nícholas F. de Camargo ${ }^{2,3} \cdot$ Danilo C. V. Corrêa $^{2,4}$. \\ Willian R. F. de Camargo ${ }^{1,5}$ - Emerson M. Vieira ${ }^{2,3} \cdot$ Onildo Marini-Filho $^{4} \cdot$ \\ Felipe W. Amorim ${ }^{6}$
}

Received: 23 February 2016/Accepted: 18 July 2016/Published online: 23 July 2016

(C) Springer International Publishing Switzerland 2016

\begin{abstract}
As biodiversity loss rapidly increases through habitat degradation in the Amazon rainforest, the need to characterize and understand the species diversity becomes even more important. In this study we used empirical and published datasets to assess the diversity patterns and produce the first overview of the sphingid fauna in the Brazilian Amazon. We compared the diversity patterns in distinct areas in the biome by analyzing hawkmoth assemblages considering both species composition and abundance, and asked whether these communities are structured according to environmental factors. Additionally, we provide information of diel activity pattern of
\end{abstract}

Electronic supplementary material The online version of this article (doi:10.1007/s10841-016-9894-6) contains supplementary material, which is available to authorized users.

Nícholas F. de Camargo

camargonf@gmail.com

Embrapa Cerrados, Rodovia BR 020, km 18, CP 08223, Planaltina, DF 73310-970, Brazil

2 Pós-graduação em Ecologia, Universidade de Brasília, Brasília, DF, Brazil

3 Laboratório de Ecologia de Vertebrados, Departamento de Ecologia, Instituto de Ciências Biológicas, Universidade de Brasília (UnB), CP 04457, Brasília, DF 70919-970, Brazil

4 Centro Nacional de Pesquisa e Conservação da Biodiversidade do Cerrado e Caatinga - CECAT, Instituto Chico Mendes de Conservação da Biodiversidade - ICMBio, IBAMA, SCEN Trecho 2, Brasília, DF 70818-900, Brazil

5 Pós-Graduação em Zoologia, Universidade de Brasília - UnB, Brasília, DF, Brazil

6 Departamento de Botânica, Instituto de Biociências, Universidade Estadual Paulista "Júlio de Mesquita Filho", Distrito de Rubião Junior s/n, Botucatu, São Paulo 18618-970, Brazil sphingids and evaluated the importance of time in sampling effort. We found that the Brazilian Amazon may harbor more than $80 \%$ of the hawkmoth species that occur in Brazil and more than half of the species recorded in South America. Species composition and assemblage structure is determined by the quality of the habitat (disturbed or undisturbed vegetation), temperature and relative humidity. Finally, we show that the temporal activity of sphingids presents distinct patterns at different taxonomic levels, highlighting the importance of full night collections to better characterize the fauna. Our results show that habitat alteration can be an important factor affecting sphingid assemblages, illustrating the importance of Protected Areas in species maintenance.

Keywords Amazon · Hawkmoth assemblage · Lepidoptera $\cdot$ Species richness - Temporal activity Tropical forest

\section{Introduction}

Recent estimates point to the occurrence of $60,000-80,000$ species of Lepidoptera in Brazil (Duarte et al. 2012). Among lepidopterans, moths of the Sphingidae family can be considered of great ecological and economic relevance because these moths are pollinators when adults (e.g., Nilsson et al. 1985; Steen 2012; Freitas and Pinheiro 2012; Martins and Johnson 2013; Xiong et al. 2015) and agricultural pests during the larval stage (e.g., Lange and Bronson 1981; Ballesteros-Mejia et al. 2011; Tanzubil 2015). Additionally, this moth family is considered a useful environmental indicator due to its relatively well-understood taxonomy, fast response to environmental changes and easy sampling methods (Hilty and Merenlender 2000). 
Worldwide, there are about 1,470 hawkmoth species (Nieukerken et al. 2011). Although hawkmoths are found on all continents and island groups, with the exception of Antarctica, the largest concentration of species is observed in tropical areas (Kitching and Cadiou). This family is globally well studied (Kitching and Cadiou 2000; Kawahara et al. 2009), however there is no consensus on the actual number of species in Brazil, possibly due to sampling insufficiency and also some taxonomic uncertainties. More recent estimates indicate at least 186 species for Brazil, which comprises about $62 \%$ of the South American richness (Kitching and Cadiou 2000; Amorim et al. 2009).

As biodiversity loss increases through habitat degradation, the need to characterize species diversity becomes even more important (Landau et al. 1999; Joppa et al. 2011). In this sense, considering the rapid change in land cover in the Amazon biome since the early 70s (Skole et al. 1994), the need is critical for more field data to better characterize species composition and abundance of sphingid moths in such a highly diverse and threatened ecosystem. Predictive models suggest that $55 \%$ of the original land cover of the Amazon will be changed in the next 15 years (Nepstad et al. 2008). Despite its important contribution to a large portion of global diversity, the Brazilian Amazon has only approximately $30 \%$ of its diversity characterized (Salati et al. 2006). The precarious access and the huge land area of the biome can be considered the most limiting factors that make studies difficult in this region. On most occasions, fluvial transport is the only way to move long distances between research institutes and study areas, making research expensive and difficult.

Published studies using sampling methods of sphingid moths in the Brazilian Amazon are very few, with only eight studies available that aimed describe richness and species composition (Rothschild and Jordan 1910; Moss 1920; Motta et al. 1991, 1998; Motta and Andreazze 2001, 2002; Motta and Xavier-Filho 2005; Hawes et al. 2009). For more accurate studies, long-term (e.g., Landau et al. 1999) and full-night field data collection are needed to better understand diversity patterns and changes in species composition and abundance (e.g., Pinheiro et al. 2002; Beck et al. 2006a). Full-night field data collection is an important and usually neglected aspect, since species flight times are not evenly distributed through the night, and exhibit different peaks of activity (Motta and Andreazze 2002; Camargo et al. 2016). This basic knowledge regarding temporal activity of hawkmoths can be important to help researchers concentrate sampling efforts into optimal periods, ensuring better characterization and monitoring of the diversity.

For the Amazon rainforest, however, there is no comprehensive information on the distribution and diversity patterns of hawkmoths (Vanhove et al. 2012). Thus, comparing how diversity patterns differ among distinct localities can be particularly important, especially considering the huge land area of the Amazon rainforest, which forms a large portion of land outside legally protected areas (PAs) that can be affected by urban zones. Among the studies carried out in this biome, only one has addressed the effects of landscape disturbance on sphingid community composition and structure (Hawes et al. 2009). However, largescale comparisons are still needed to better understand how these moths respond to disturbance and to determine how effective are PAs in the conservation and maintenance of hawkmoths in the Amazon. Comparing distinct areas can also provide insights regarding how abiotic factors determine temporal and spatial species distributions in the biome. Factors such as temperature, humidity, altitude and wind speed can all affect composition (e.g. Brehm and Fiedler 2003; Beck et al. 2006a; Axmacher et al. 2009; Ferro and Melo 2011; Ignatov et al. 2011), survival (e.g., Liu et al. 2002; Contreras et al. 2013), reproduction (e.g., Zhang et al. 2013) and displacement (e.g., Chapman et al. 2008; Hernández et al. 2010) of Lepidoptera.

In this study, we used empirical and published datasets to assess diversity patterns of hawkmoths in the Amazon rainforest. Our objectives were fourfold: (1) to provide the first overview of species composition and diversity of hawkmoths in the Amazon biome and to estimate how many species are to be expected in this highly diverse biome; (2) to compare the diversity patterns among distinct regions in the Amazon rainforest; (3) to investigate the relevance of environmental factors in structuring sphingid assemblages; and (4) to provide information of the diel activity pattern of sphingids, thus highlighting the importance of considering time of the day in sampling efforts. To this end, we used long-term and full-night field data collections conducted in the Amazon rainforest in conjunction with published data from distinct localities of the biome.

\section{Methods}

\section{Study area}

The Amazon biome covers nine countries in South America, with $69 \%$ of its extent inside Brazilian territory, covering 4,871,000 $\mathrm{km}^{2}$ (Ab'Saber 1977). The pluviometric regime has great spatial and temporal variation. However, in general, rainfall is present all year round, with an increase in precipitation during November to March (Figueroa and Nobre 1990).

Field data collection took place at the Serra do Pardo National Park (SPNP), in mid-west Pará state in the Brazilian Amazon, located between the municipalities of 
Altamira and São Félix do Xingu, in the region known as Terra do Meio ("middle land" in Portuguese). The Terra do Meio is a broad area located between the Xingu and Iriri rivers in the southwest of Pará state and covers about $8 \times 10^{6}$ ha. This region has been suffering continuous deforestation and is a conflict area for land and expansion of cattle farming (Ramos et al. 2014). The SPNP has an area of 445,392 ha comprised of open and closed submontane rain forests and campo cerrado, i.e., open vegetation of Neotropical savanna (Ratter et al. 2003).

\section{Sampling methods and sphingid fauna compilation}

Moths were attracted by light-traps composed of two $1.5 \times 2.0 \mathrm{~m}$ white fabric sheets arranged in an L-shape suspended from aluminum bars, and illuminated by two $250 \mathrm{~W}$ lamps constituted of mercury-vapor with tungsten filaments, powered by portable generators (as described by Camargo and Cavalcanti 1999). Each sampling event started at sunset and ended at sunrise, and consisted of approximately 12 consecutive hours of collection per night. Data collection took place during 2010 and 2011 in five sampling periods (I, II, III, IV and V) distributed across 14 sampling points in a transect of $43 \mathrm{~km}$ along the Xingu River, totaling 149 trapping nights (Fig. 1).

We killed collected moths by injecting ammonia into the ventral part of the thorax then packed them into entomological boxes for transport. In the laboratory, each moth was mounted, identified and deposited in the entomological collection of the Research Center for the Cerrado of the Brazilian Agricultural Research Corporation (Embrapa Cerrados), Brasília, Federal District, Brazil. Species identifications were made with reference to illustrations and identification keys (D’Abrera 1986; Moré et al. 2005), and, when necessary, by means of genitalia examination. Nomenclature and classification follow Kitching and Cadiou (2000).

To compile a list of the sphingid species occurring in the Amazon, we also used available data from 13 published references (see Online Resource 1 for more details). In cases of inconsistencies with regard to recent known species distributions, and taxonomic synonyms, especially for the older studies, we excluded questionable species identifications from the final list.

\section{Diversity pattern analyses}

To analyze sphingid diversity patterns and compare distinct locations in the Amazon, we considered the data set obtained in the SPNP, in conjunction with eight studies conducted in nine distinct localities, for which sphingid faunal compositions were available, as follows (author: locality): (1) Rothschild and Jordan (1910): Madeira River $\left(8^{\circ} 38^{\prime} \mathrm{S}, 63^{\circ} 49^{\prime} \mathrm{W}\right)$; (2) Moss (1920): Belém $\left(1^{\circ} 26^{\prime} \mathrm{S}\right.$, $\left.48^{\circ} 29^{\prime} \mathrm{W}\right)$; (3) Motta et al. (1991): Macará Island $\left(3^{\circ} 25^{\prime} \mathrm{N}\right.$, $\left.61^{\circ} 39^{\prime} \mathrm{W}\right)$, and Pacaraima Mountains $\left(3^{\circ} 38^{\prime} \mathrm{N}, 61^{\circ} 32^{\prime} \mathrm{W}\right)$; (4) Motta et al. (1998): Itacoatiara ( $\left.3^{\circ} 1^{\prime} \mathrm{S}, 58^{\circ} 49^{\prime} \mathrm{W}\right)$; (5) Motta and Andreazze (2001): Jaú National Park (JNP-2 ${ }^{\circ}$ $\left.7^{\prime} \mathrm{S}, 61^{\circ} 43^{\prime} \mathrm{W}\right)$; (6) Motta and Andreazze (2002): São Gabriel da Cachoeira (SGC-1 ${ }^{\circ} 4^{\prime} \mathrm{N}, 69^{\circ} 50^{\prime} \mathrm{W}$ ); (7) Motta and Xavier-Filho (2005): Beruri $\left(3^{\circ} 58^{\prime} \mathrm{S}, 61^{\circ} 25^{\prime} \mathrm{W}\right)$; and 8 ) Hawes et al. (2009): Jarí River $\left(0^{\circ} 53^{\prime} \mathrm{S}, 52^{\circ} 36^{\prime} \mathrm{W}\right.$ ) (see Fig. 1 for more details).

To estimate the total sphingid richness in the Brazilian Amazon rainforest as whole, we used first-and secondorder Jackknife methods, which use incidence data of species occurrences. We opted to use incidence-based estimators because two of the eight available studies (Moss 1920; Rothschild and Jordan 1910) included only species occurrence, not abundance data. Species-richness estimators such as the Jackknife are dependent on sample size, producing higher estimates as sampling effort increases (Melo 2004), especially considering that each study had very distinct sampling effort. However, we were able to present a lower limit for the total number of species.

For comparing richness patterns among areas we used individual-based rarefaction curves using the software EstimateS 9.1 (Colwell 2013). This analysis was conducted on eight localities using our field data collection in addition to that from the six published studies that included species abundance data. We used two approaches: (1) Rarefy down all assemblages based on three times the abundance of the smallest sample (102 individuals; Hawes et al. (2009)). Extrapolation above this range yields very wide confidence intervals hindering statistical comparisons between samples (Colwell et al. 2012); (2) Produce curves with richness extrapolated to 9000 individuals based on our captures in the SPNP, which was the study with the greatest hawkmoth abundance. Although this leads to inaccuracy of statistical comparisons among assemblages, we used this exploratory approach to compare the rate at which new species are discovered during sampling with maximum standardized abundances, and a projection of richness in each locality.

To investigate similarity in species diversity among localities, first we estimated the "true" species richness for those localities which abundance data were available. We calculated the "true" species richness using the bias-corrected version of Chao 1 estimator, and ACE (abundancebased coverage estimator of species richness). Both abundance-based methods take account of the number of rare species to estimate the number of unseen species in the assemblage (Gotelli and Chao 2013). While the Chao 1 estimator uses as rare species the numbers of singletons and doubletons (i.e., species with only one and two individuals, respectively), the ACE estimator uses an upper abundance limit $k$ for rare or infrequent species to estimate 


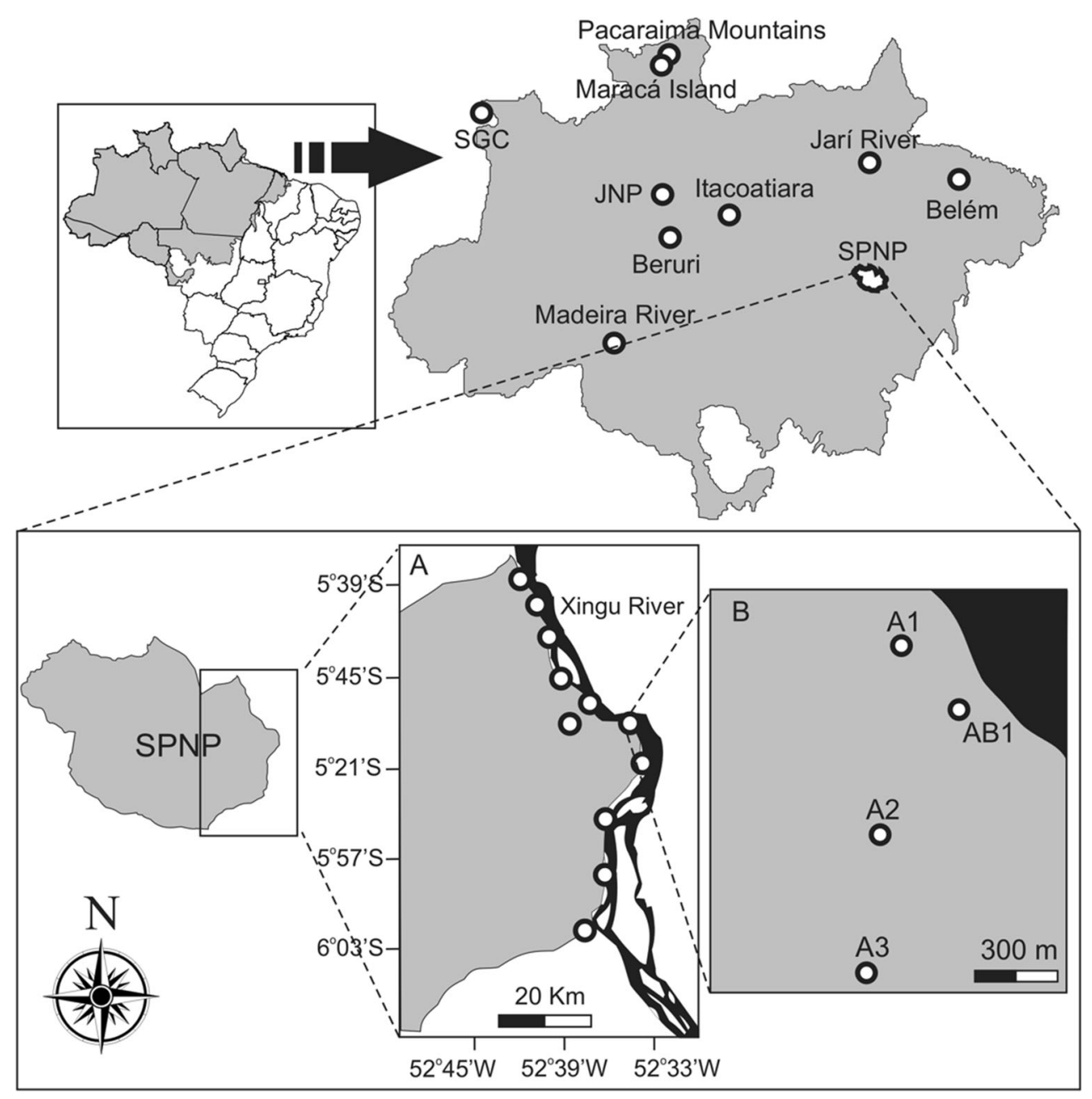

Fig. 1 Localities of the studies conducted in the Brazilian Amazon rainforest (shown as the grey area on the map) that were used to compare sphingid diversity: Madeira River (Rothschild and Jordan 1910); Belém (Moss 1920); Maracá Island and Pacaraima Mountains (Motta et al. 1991); Itacoatiara (Motta et al. 1998); Jaú National Park (JNP) (Motta and Andreazze 2001); São Gabriel da Cachoeira (SGC) (Motta and Andreazze 2002); Beruri (Motta and Xavier-Filho 2005); Jarí River (Hawes et al. 2009); and Serra do Pardo National Park (SPNP) (this study). The lower insets show the sampled sites in the

species richness. We used 10 as the upper abundance limit for rare or infrequent species to calculate ACE (see Colwell 2013; Gotelli and Chao 2013). Second, to ensure that only well sampled localities were used in the similarity analysis, we included only those studies which the observed richness represented at least $70 \%$ of the "true" species richness estimated. For the comparisons among localities, we followed the ordination method proposed by Ferro and Melo (2011) to investigate the robustness of the analysis. This procedure is similar to rarefaction, which standardizes species richness to a common sample size (i.e., number of species). Thus, we randomly sampled a subset of species based on the locality with the lowest richness and
Serra do Pardo National Park: inset ' $A$ ' shows the 11 sites sampled along the Xingu River (sampling period V-September 22 to October 02, 2011), each sampled for a single night; inset ' $B$ ' shows the sampled sites in period I ( $A 1, A 2$ and $A 3)$, II, III and IV ( $A 2, A 3$ and $A B 1$ ). Sampling period I was conducted for seven nights (April 07 to 14, 2010), and sampling periods II (May 11 to 23, 2010), III (September 01 to 13, 2010) and IV (November 28 to December 10, 2010) for 13 nights at each site

computed the Jaccard and the Bray-Curtis dissimilarity indices among areas. We chose the Jaccard index for comparing localities based only on species incidence (i.e., presence and absence), and the Bray-Curtis index to also take account of the species abundance. Using these distinct similarity matrices, we performed two Principal Coordinates Analysis (PCoA), one for each matrix. This procedure was repeated 10,000 times and we performed a Procrustes analysis to compare each of these ordinations with the ordination using the full data set. A Procrustes analysis rotates a matrix (i.e., subset of species) to attain maximum similarity with a target matrix (i.e., full data set) by minimizing the sum of squared differences. To 
summarize the comparisons, we calculated the mean values of the Procrustes scores to obtain mean score values of the subsamples on the first two PCoA axes (PCoA1 and PCoA2). Then, we graphically compared the ordination of the full data set and each of the 10,000 ordinations using subsamples. The PCoA and Procrustes analyses were performed in software R v.3.2.1 (R Development Core Team 2014) using the package vegan (Oksanen et al. 2015). We also performed Kernel density estimates as a visual exploratory technique to represent graphically the densities of the 10,000 ordinations using the package ggplot 2 (Wickham and Chang 2015).

\section{Environmental factors and the structure of sphingid assemblages}

To assess the environmental factors that could potentially determine Sphingidae composition and diversity, we used five environmental variables obtained from the Bank of Meteorological Data for Education and Research of IMET (2015): maximum wind speed, maximum temperature, minimum temperature, mean temperature and relative humidity. We obtained monthly means from 1961 to 2014 for each area, and then calculated a mean value for each variable. Meteorological stations were located between 50 and $130 \mathrm{~km}$ from sampling sites. We also included altitude of the sampled areas derived from Google Earth v. 7.1.5.1557 (Google Inc. 2015). Additionally, depending on the information in the studies used in the analysis, we included a binary variable indicating whether sampling of moths was conducted in disturbed (1) or undisturbed (0) vegetation.

Then, we conducted a Constrained PCoA using both Jaccard and Bray-Curtis dissimilarities. This analysis is similar to Redundancy Analysis, but permits the use of dissimilarity matrices. Before conducting the constrained PCoA, we first performed a model selection analysis using the Akaike Information Criterion (AIC) to explore the set of environmental variables that most explain the similarities among localities. We chose the model with the lowest AIC and those presenting $\triangle \mathrm{AIC}<4$ in relation to the other models (Bolker 2008). Additionally, to assess a possible spatial autocorrelation effect on the diversity and composition among areas, we performed matrix correlations (Mantel test) using the paired differences in distance between localities, calculated using Google Earth, and considering the matrices of both Jaccard and Bray-Curtis indices.

\section{Temporal activity pattern}

To investigate the diel activity of hawkmoths in the Amazon, we continuously recorded their activity patterns by capturing and counting the adults attracted to the lighttraps. We used moths collected at SPNP in sampling periods II, III and IV, and excluded those from sampling periods $\mathrm{I}$ and $\mathrm{V}$, as on the first occasion abundance data were too low to conduct the analysis, while on the last, data collection took place at different locations along the Xingu River during each sampling day (see Fig. 1 for more details).

For chronobiological descriptions, we considered three taxonomic levels: the entire family, subfamilies and tribes. We first pooled moth occurrences into $1-\mathrm{h}$ intervals, and calculated average percentages of captured individuals in sampling periods II, III and IV (see Fig. 1) and illustrated the results graphically to show daily activity at each taxonomic level, and considering both the proportion of individuals (i.e., abundances) and the proportion of species sampled in each hour interval (i.e., richness). For pairwise comparisons of activity patterns within subfamilies and tribes, we performed the Kolmogorov-Smirnov test using the software Past 2.17c (Hammer et al. 2001).

\section{Results}

\section{Hawkmoth composition and diversity patterns}

In total (considering both our empirical data and those from the literature) we recorded the occurrence of 128 sphingid species (Online Resource 1). We opted to exclude from our species list and from all of our analyses the species Manduca leucospila (found in Motta and Andreazze 2001), $M$. pellenia (found in Motta et al. 1998; Motta and Andreazze 2002) and Isognathus rimosa (found in Motta et al. 1998; Motta and Andreazze 2001; Motta and Andreazze 2002), since these species probably are misidentifications considering their distributions (e.g., Kitching 2015), and the lack of registers in other studies in the Brazilian Amazon rainforest. Based on our results and in our knowledge considering distinct Brazilian collections, we estimate that 23 species (18\%) are restricted to the Amazon region (see Online Resource 1). Species were distributed in 29 genera, three subfamilies and five tribes. Species from the tribe Dilophonotini comprised $58 \%$ of total richness recorded in the biome, and Xylophanes (tribe Macroglossini) was the genus with the highest number of species, comprising about $19 \%$ of the total species richness (24 species). In the SPNP, we sampled 9048 individuals, comprising 90 species placed in 25 genera. Our data added three species not previously recorded for the Amazon (Online Resource 1). Estimates of "true" species richness revealed a total species richness for Amazon varying between 145 (Jackknife 1) and 150 (Jackknife 2). 
Individual-based rarefaction curves standardized to a common abundance of 300 individuals showed that the Jari River region had the highest species richness and Pacaraima Mountains the lowest (Fig. 2). Our analysis also showed that Itacoatiara and SPNP have similar richness in comparison to Pacaraima Mountains, JNP and Beruri, whereas SGC and Maracá Island have similar richness to JNP and Beruri (Fig. 2). Comparisons of species richness among localities using individual-based rarefaction curves extrapolated to 9000 individuals confirmed that Jari River has the highest richness and Pacaraima Mountains the lowest (Fig. 3). However, SGC, JNP, SPNP and Maracá Island have higher richness in comparison to Beruri and Itacoatiara (Fig. 3).

The studies conducted at Jarí River and Pacaraima Mountains had an upper limit of less than $70 \%$ of the total species richness according to Chao 1 and ACE estimators (Table 1). For this reason, we exclude these two studies from the assemblage analysis comparing localities. Considering only the localities that were compared, Beruri has the lowest richness with 46 species (Table 1); thus, this value was used as the reference to produce subsamples for the Procrustes analysis. PCoA ordinations using both Jaccard and Bray-Curtis dissimilarity indices and the entire set of species showed few differences in comparison to the average scores obtained by Procrustes axes rotation
(Fig. 4). The ordination using Jaccard dissimilarity showed that Beruri and Itacoatiara occupied positive regions of the first axis in comparison to SPNP, SGC, JNP and Maracá Island. On the second axis, from negative to positive axis values, JNP and SGC, Beruri and SPNP, and Maracá Island and Itacoatiara were more similar in species composition (Fig. 4).

\section{Environmental factors and the structure of sphingid assemblages}

According to the model selection analysis, vegetation $(\mathrm{F}=2.298, P=0.005)$, relative humidity $(\mathrm{F}=1.955$, $P=0.011)$, and minimum temperature $(\mathrm{F}=1.569$, $P=0.030)$ were the most important variables affecting hawkmoth assemblage structure (Fig. 4). The constrained PCoA $\left(\mathrm{F}_{3,2}=1.961, P=0.003\right)$ showed a very similar pattern to the unconstrained PCoA with environmental variables explaining $34 \%$ of the species composition patterns. The analysis showed that vegetation was the most correlated variable on the first axis, whereas relative humidity and minimum temperature were most correlated with the second axis (Table 2).

The ordination using Bray-Curtis dissimilarity showed that Beruri, SGC and Macará Island occupied positive regions of the first axis, and Itacoatiara, JNP and SPNP

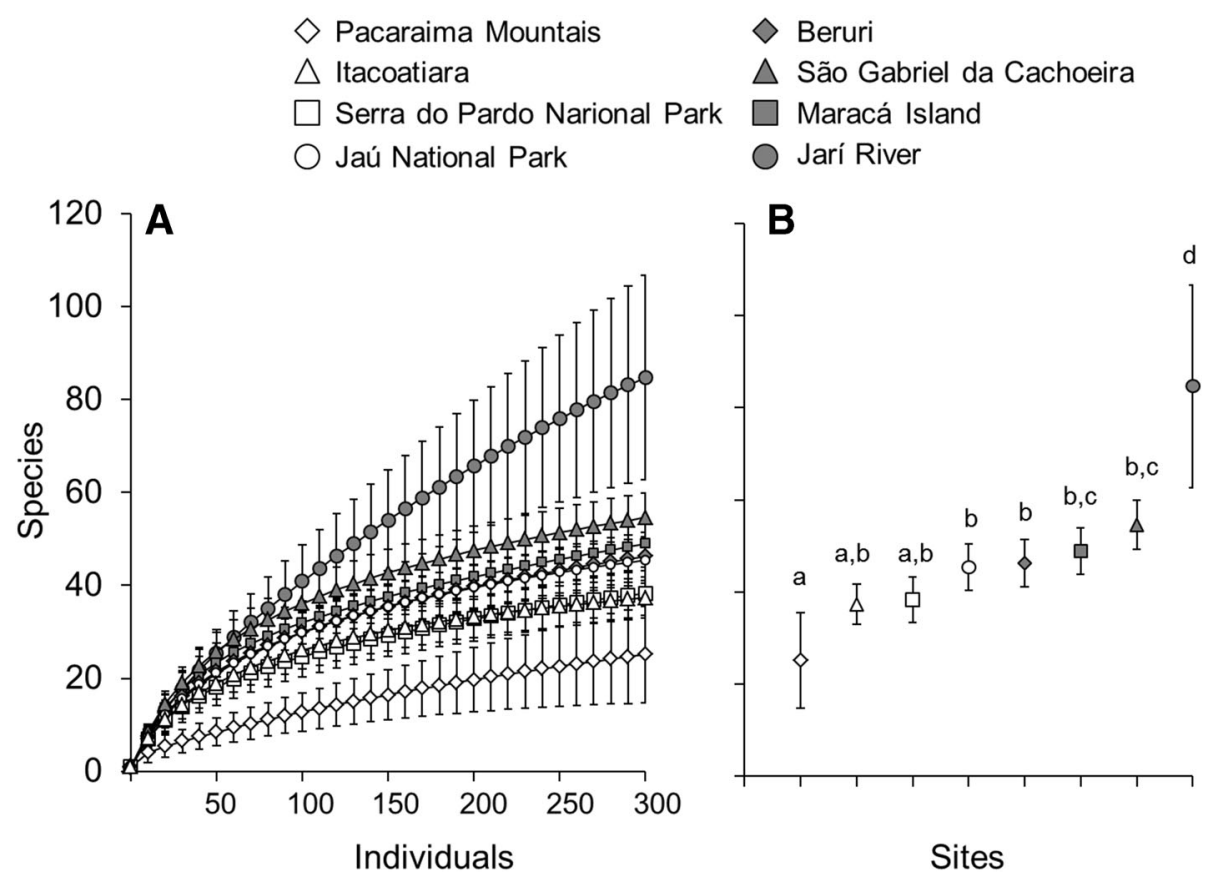

Fig. 2 Individual-based rarefaction curves for eight Sphingidae assemblages in the Brazilian Amazon rainforest: São Gabriel da Cachoeira (Motta and Andreazze 2002); Maracá Island and Pacaraima Mountains (Motta et al. 1991); Jaú National Park (Motta and Andreazze 2001); Beruri (Motta and Xavier-Filho 2005); Itacoatiara (Motta et al. 1998); Jarí River (Hawes et al. 2009); and
Serra do Pardo National Park (this study). Horizontal bars show the $95 \%$ confidence interval (CI). a shows curves rarefied down based on the study with the lowest abundance extrapolated three times (see "Methods" for further details). b shows richness using 300 sampled individuals for improved visualization of differences among areas. Letters indicate differences according to $\mathrm{CI}$ 
Fig. 3 Individual-based rarefaction curves for eight Sphingidae assemblages in the Brazilian Amazon rainforest: São Gabriel da Cachoeira (Motta and Andreazze 2002); Maracá Island and Pacaraima Mountains (Motta et al. 1991); Jaú National Park (Motta and Andreazze 2001); Beruri (Motta and Xavier-Filho 2005); Itacoatiara (Motta et al. 1998); Jarí River (Hawes et al. 2009); and Serra do Pardo National Park (this study). Thick lines indicate the number of sampled individuals for each assemblage. Dashed lines indicate the richness projection extrapolating to 9000 individuals
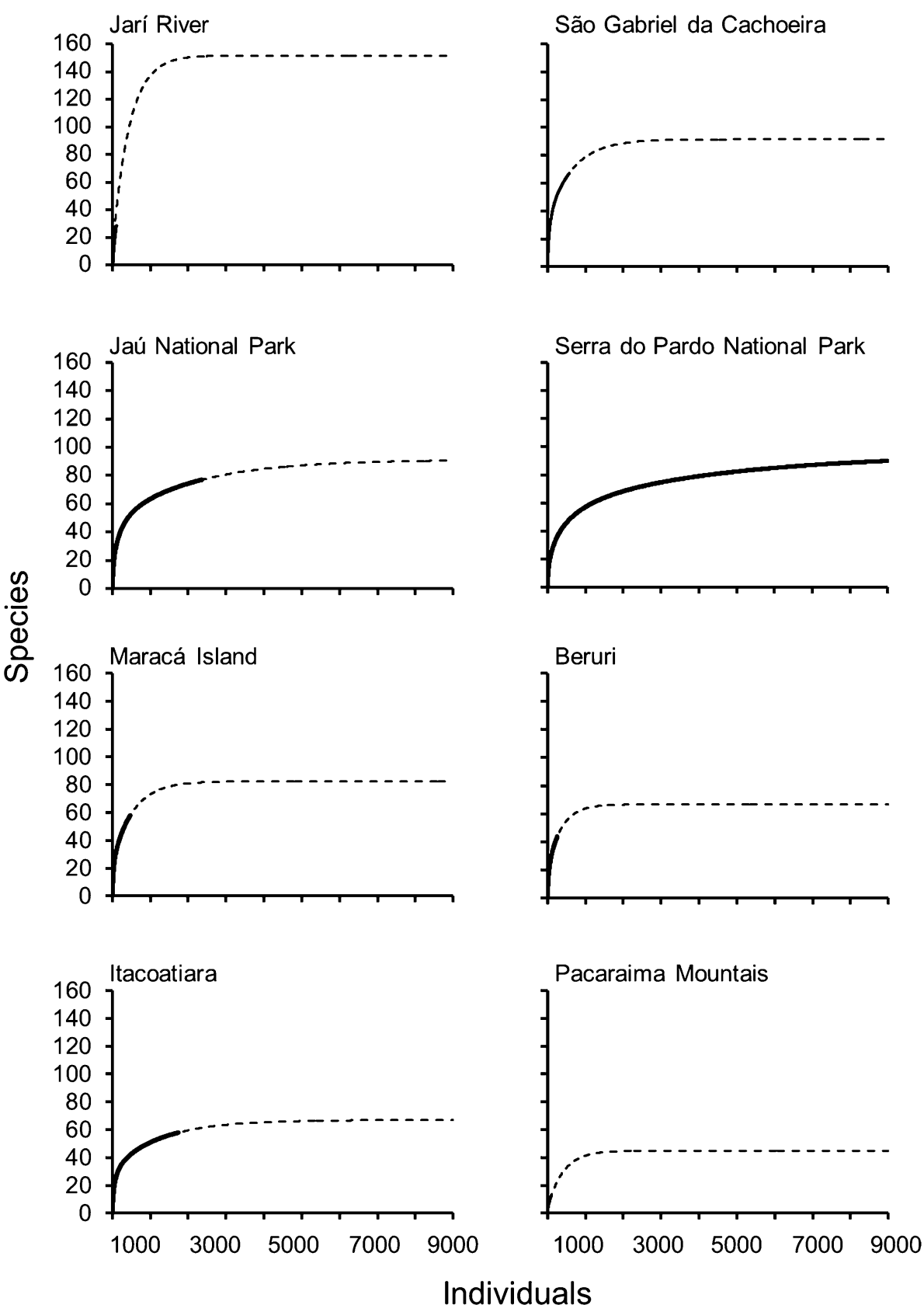

occupied the negative regions in the first axis. From negative to positive axis values, Itacoatiara and JNP, and Beruri, SGC and Macará were more similar, whereas SPNP was more isolated to the other localities (Fig. 4). The model selection showed that maximum temperature $(\mathrm{F}=3.555, P=0.031)$ was the most important environmental variable and was correlated only with the first axis (Table 2). The Constrained PCoA $\left(\mathrm{F}_{1,4}=2.550\right.$, $P=0.040$ ) showed that environmental variables explained $39 \%$ of the diversity patterns among localities. The Mantel test showed no spatial autocorrelation among areas using either Jaccard $(r=0.19 ; \quad P=0.332)$ or Bray-Curtis $(r=0.28 ; P=0.867)$ indices.

\section{Temporal activity pattern}

Diel activity for the family as a whole, and taking account of abundances, showed an increase of activity through the night, with three main peaks during 21:00, 01:00 and 05:00 h (Fig. 5a), with the last two showing the highest moth activity. Among the three subfamilies evaluated (Fig. 5b), Macroglossinae had a diel activity very similar to the family as a whole, with increasing activity through the night and peaks at 21:00, 01:00 and 05:00 h. This pattern was distinct from those of the other two subfamilies (Sphinginae and Smerinthinae). Our results from pairwise comparisons showed that all subfamilies differed in diel 
Table 1 Observed $\left(\mathrm{S}_{\mathrm{obs}}\right)$, richness estimates using Chaol and ACE methods, and lower and upper percentage richness found in each locality according to these estimators. Motta et al. (1991): Macará Island and Pacaraima Mountains; Motta et al. (1998): Itacoatiara; Motta and Andreazze (2001): Jaú National Park (JNP); Motta and Andreazze (2002): São Gabriel da Cachoeira (SGC); Motta and Xavier-Filho (2005): Beruri; Hawes et al. (2009): Jarí River; Serra do Pardo National Park (SPNP): this study

\begin{tabular}{lcrrl}
\hline Locality & $\mathrm{S}_{\mathrm{obs}}$ & Chao 1 & ACE & Percentage range \\
\hline Beruri & 46 & 63 & 66 & $70-73$ \\
Itacoatiara & 57 & 64 & 67 & $85-89$ \\
Jarí River & 39 & 120 & 119 & $32-33$ \\
JNP & 76 & 88 & 91 & $84-86$ \\
Maracá Island & 58 & 79 & 94 & $62-73$ \\
Pacaraima Mountais & 13 & 27 & 36 & $36-48$ \\
SGC & 66 & 85 & 85 & 77 \\
SPNP & 90 & 93 & 97 & $93-97$ \\
\hline
\end{tabular}

Table 2 Correlations of the most important environmental variables of constrained principal coordinates analyses using Jaccard and BrayCurtis dissimilarities evaluating six sphingid assemblages from localities in the Amazon rainforest (see Fig. 4 for more details)

\begin{tabular}{llllll}
\hline & \multicolumn{2}{l}{ Jaccard } & & \multicolumn{2}{l}{ Bray-Curtis } \\
\cline { 2 - 3 } \cline { 6 - 7 } \cline { 5 - 6 } & PCoA1 & PCoA2 & & PCoA1 & PCoA2 \\
\hline Humidity & 0.38 & $\mathbf{- 0 . 8 8}$ & & - & - \\
Maximum temperature & - & - & & $\mathbf{- 0 . 9 8}$ & 0.00 \\
Minimum temperature & 0.23 & $\mathbf{- 0 . 6 6}$ & - & - \\
Vegetation & $\mathbf{- 0 . 8 1}$ & $\mathbf{- 0 . 4 2}$ & - & - \\
\hline
\end{tabular}

Numbers in bold represent the most correlated variables on each axis $(\mathrm{r} \geq 0.5)$

activity pattern (Table 3 ). Considering the sampled individuals of the various tribes (Fig. 5c), we observed three basic patterns: a very clear maximum temporal activity at 01:00 $\mathrm{h}$ for the tribes Acherontiini and Ambulycini; an
Fig. 4 Principal coordinates analyisis (PCoA) (a) and Constrained PCoA (b) using Jaccard and Bray-Curtis dissimilarities of Sphingidae assemblages from six localities in the Amazon rainforest: São Gabriel da Cachoeira (Motta and Andreazze 2002); Maracá Island (Motta et al. 1991); Jaú National Park (Motta and Andreazze 2001); Beruri (Motta and Xavier-Filho 2005); Itacoatiara (Motta et al. 1998); and Serra do Pardo National Park (this study). In the PCoA, black symbols indicate the ordination using all species in each locality and white symbols indicate averages of 10,000 subsample ordinations containing 46 species that were submitted to Procrustes analysis (see "Methods" for more details). Darker areas indicate higher density regions according to Kernel density estimates based on the 10,000 subsamples ordinations. Humidity = relative humidity; MaxTemp $=$ maximum temperature;

MinTemp $=$ minimum temperature;

Vegetation $=$ disturbed or undisturbed vegetation
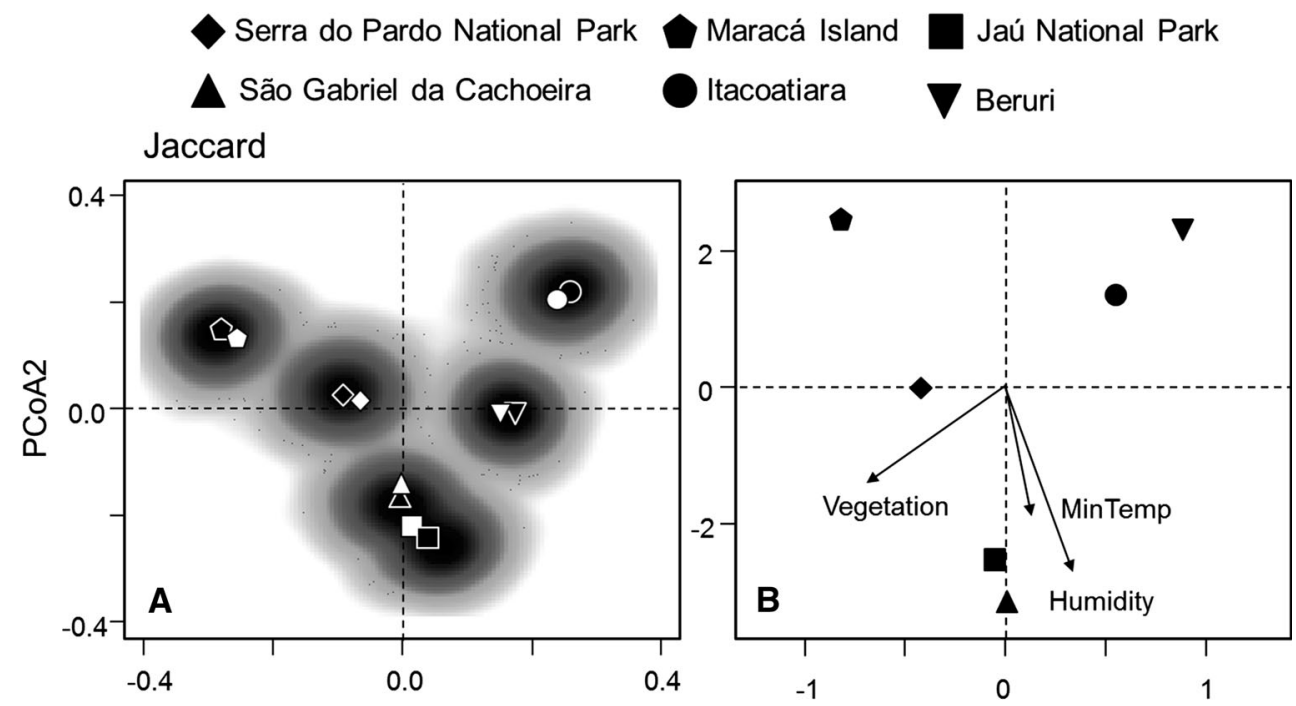

Bray-Curtis
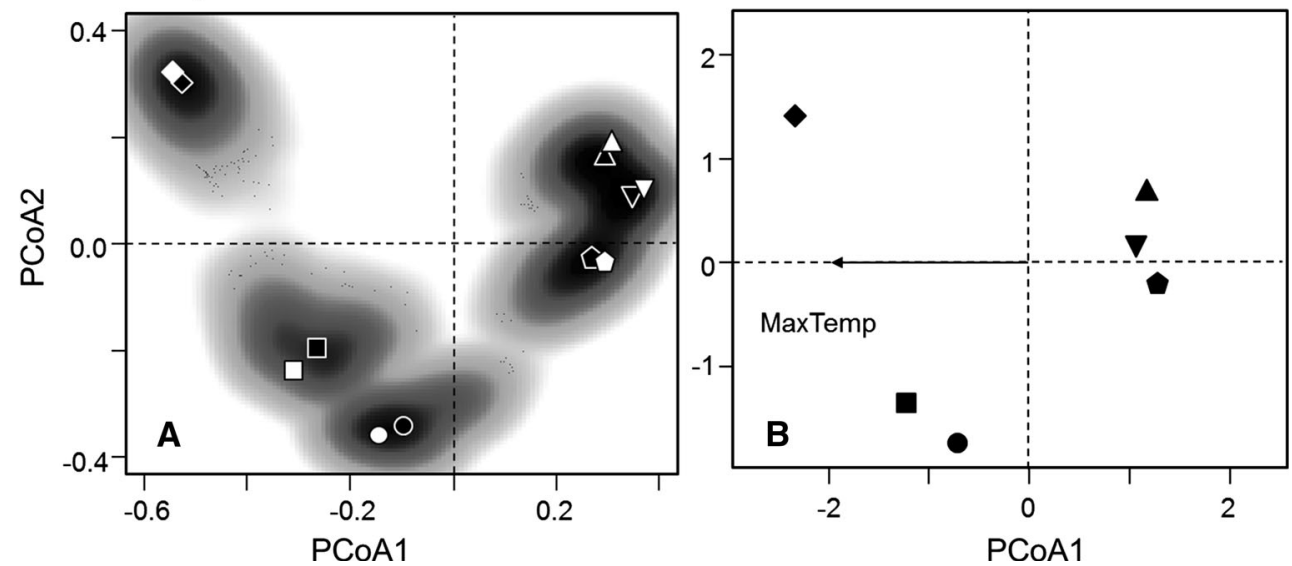

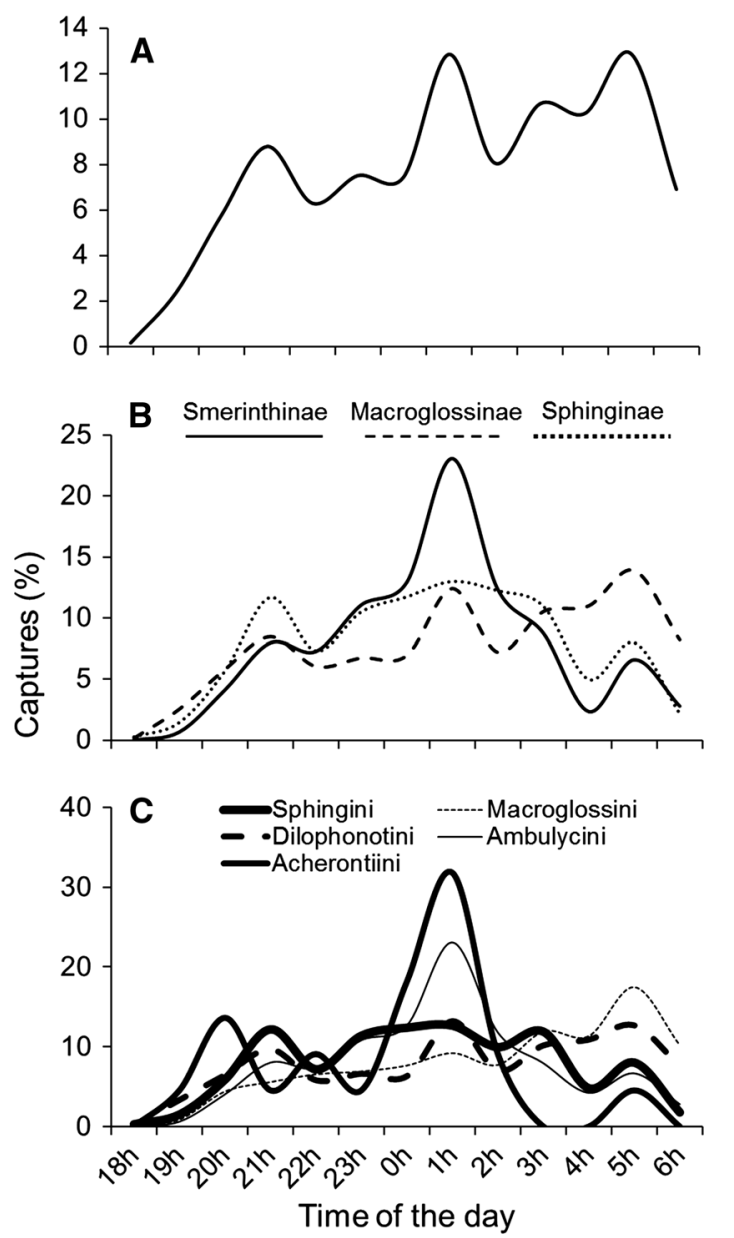

Fig. 5 Temporal activity of Sphingidae sampled in the Brazilian Amazon rainforest at the Serra do Pardo National Park, taking account of moth abundances in each hour interval. a activity pattern for the entire family; b activity pattern for subfamilies; c activity patterns for tribes

increase of temporal activity through the night with a peak at 05:00 $\mathrm{h}$ for the tribes Dilophonotini and Macroglossini; and a very similar temporal activity for tribe Sphingini in comparison to subfamily Sphinginae as a whole. According to our pairwise comparisons, only the tribes Macroglossini and Dilophonotini did not differ in temporal activity pattern considering abundances (Table 3 ).

With regard to species richness for the family as a whole, we confirmed that this is relatively constant throughout the night from 21:00 to 05:00 h (Fig. 6a). At subfamily level, Macroglossinae showed a pattern of temporal richness very similar to that for the family (Fig. 6b). However, whereas Sphinginae richness had peaks at 00:00 h, 03:00 h and 05:00, Smerinthinae had peaks at 21:00, 01:00 and 04:00 h. Our pairwise comparison also showed that all subfamilies differ in patterns of temporal richness (Table 3). Regarding tribes (Fig. 6c), very distinct temporal activity patterns were observed. Dilophonotini had two main peaks: one between 21:00 $\mathrm{h}$
Table 3 Pairwise comparisons of activity patterns of Sphingidae at subfamily and tribal levels with regard to the three sampling sessions conducted in Serra do Pardo National Park (see "Methods" for more details)

\begin{tabular}{llll}
\hline & MG & SM & SP \\
\hline Subfamily & & & \\
Richness & & & \\
$\quad$ Macroglossinae (MG) & - & & \\
Smerinthinae (SM) & 0.0001 & - & - \\
Sphinginae (SP) & 0.0001 & 0.0004 & \\
Abundance & & & \\
$\quad$ Macroglossinae (MG) & - & & \\
Smerinthinae (SM) & 0.0001 & - & - \\
Sphinginae (SP) & 0.0001 & 0.033 & SP \\
\hline
\end{tabular}

Tribe

Richness

\begin{tabular}{|c|c|c|c|c|c|}
\hline Ambulycini (AB) & \multicolumn{3}{|l|}{-} & & \\
\hline Dilophonotini (DP) & \multicolumn{2}{|c|}{0.0001} & - & & \\
\hline Macroglossini (MG) & \multicolumn{2}{|c|}{0.0007} & 0.0001 & \multicolumn{2}{|l|}{-} \\
\hline \multirow[t]{2}{*}{ Sphingini (SP) } & \multicolumn{2}{|c|}{0.0005} & 001 & 0.010 & - \\
\hline & $\mathrm{AC}$ & $\mathrm{AB}$ & DP & MG & SP \\
\hline \multicolumn{6}{|l|}{ Abundance } \\
\hline Acherontiini (AC) & - & & & & \\
\hline Ambulycini (AB) & 0.0003 & - & & & \\
\hline Dilophonotini (DP) & 0.0001 & 0.0001 & - & & \\
\hline Macroglossini (MG) & 0.0001 & 0.0005 & 0.063 & - & \\
\hline Sphingini (SP) & 0.0002 & 0.0002 & 0.0001 & 0.0001 & - \\
\hline
\end{tabular}

Results for Acherontiini richness are not shown because this tribe is represented by only one species. Values correspond to $P$ values obtained via Kolmogorov-Smirnov tests using abundance and richness data. Statistically insignificant values $(P>0.05)$ are in bold

and one at 05:00 h; Macroglossini had a peak mainly between 22:00 and 00:00 h, remaining stable until 04:00 h, with a smaller peak at 5:00 h; Sphingini had three clear peaks at 21:00, 00:00 and 05:00 $\mathrm{h}$; Ambulycini were more active mainly at 01:00 h, although this tribe also had smaller peaks at 21:00 and 04:00 h. All tribes also presented differences in the temporal activity patterns considering richness (Table 3 ).

\section{Discussion}

\section{Diversity patterns}

Sphingid species richness recorded in the Brazilian Amazon (128 species) represents about $70 \%$ of the total species richness estimated for Brazil (186 species), and more than 

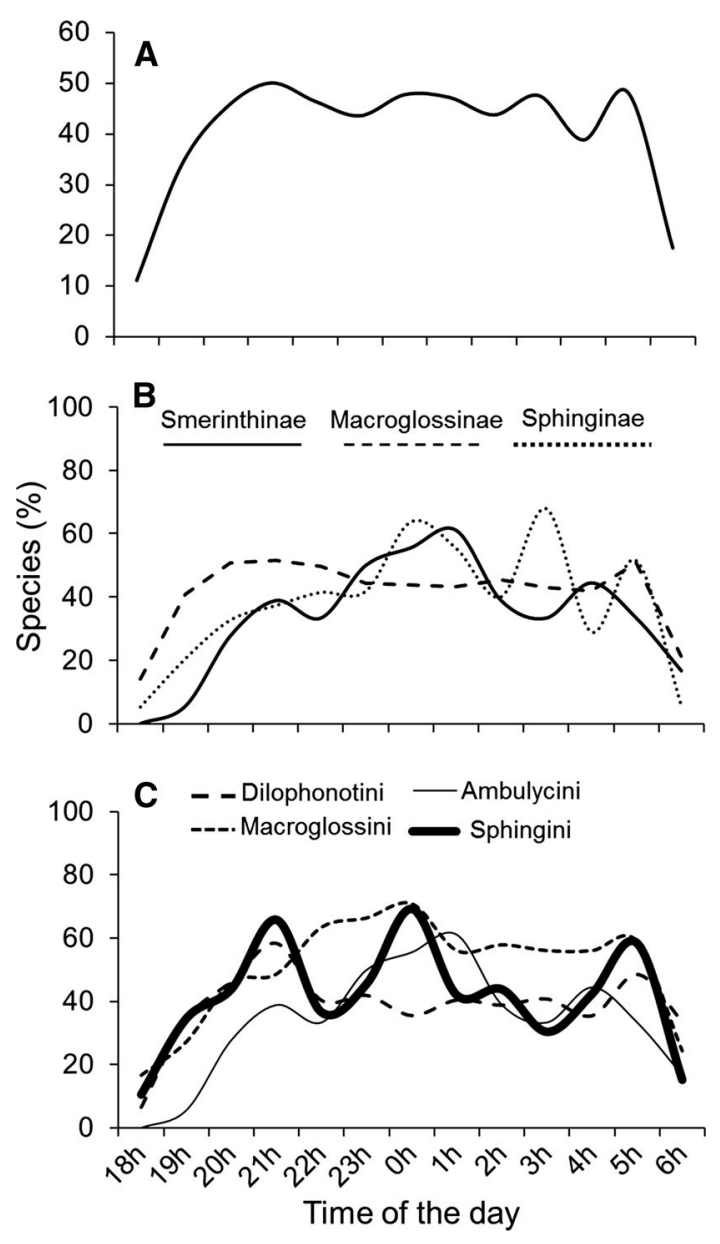

Fig. 6 Temporal activity of Sphingidae sampled in the Amazon rainforest at the Serra do Pardo National Park taking account of moth richness in each hourly interval. a activity pattern for the entire family; $\mathbf{b}$ activity patterns of subfamilies; $\mathbf{c}$ activity patterns for tribes

$40 \%$ of South America (302 species). However, considering the estimates of "true" species richness (145-150 species), the biome may enclose about $80 \%$ of sphingids recorded in Brazil, and half of the total diversity of the South America (Kitching and Cadiou 2000; Amorim et al. 2009), and about $10 \%$ of the global richness of Sphingidae.

Individual-based rarefaction showed two regions with very distinct richness patterns: Jarí River with the highest species richness and Paracaraima Mountains with the lowest. This pattern was observed in both analytical approaches (rarefied down and extrapolated curves). The low richness of the Pacaraima Mountains may, in turn, be attributable to the low sampling effort undertaken in this area. Whereas one expedition of 10 days was conducted in the Pacaraima Mountains, nine expeditions of five to 10 days were conducted on Maracá Island (Motta et al. 1991). Indeed, this agrees with our results, which indicate that the sphingids sampled in the Pacaraima Mountains represent only $36-48 \%$ of the estimated richness according to Chao 1 and ACE. However, other factors, such as altitude and vegetation type, may also explain the lower species richness observed in Pacaraima Mountains, since the study at this location was conducted in an area of savanna-like vegetation (Cerrado) into the Amazon region ca. 1200 m a.s.l. (Nunes et al. 1988; Motta et al. 1991).

Rarefaction analyses, however, did not reveal significant differences among the other localities. Although, when comparing the extrapolated richnesses, we found that National Parks (JNP and SPNP) and localities distant from cities (SGC and Maracá Island), tend to have higher richness than localities outside PAs and near to cities (e.g., Beruri and Itacoatiara). Whereas sphingid sampling in SGC (Motta and Andreazze 2002) and Maracá Island (Motta et al. 1991) was conducted in primary forests, sampling in Itacoatiara and Beruri was conducted in disturbed areas containing pasture (Motta et al. 1998) and plantations of the native fruit tree, cupuaçu (Theobroma grandiflorum) (Motta and Xavier-Filho 2005).

\section{The effect of habitat on sphingid assemblage structure}

The availability of forest habitats is an important determinant of sphingid richness (Beck et al. 2006b); hence the high richness found in our study was expected, since the Brazilian Amazon rainforest contains about $40 \%$ of the world's remaining tropical rainforest. Also, the Amazon is the most diverse of the all tropical forest wilderness areas in the world (Laurance et al. 2001; Da Silva et al. 2005). However, other factors such as temperature, altitude and habitat heterogeneity are also known to affect species composition and abundance, as well as diversity patterns of the sphingid fauna (e.g., Liu et al. 2002; Ferro and Melo 2011; Zhang et al. 2013). The highest species richness was observed on the Jarí River, which includes both primary and secondary forest areas, as well as a Eucalyptus plantation (Hawes et al. 2009). Such habitat heterogeneity, encompassing both pristine and disturbed areas, may include both more restricted and habitat sensitive species and more generalist ones that are less sensitive to disturbances, resulting in a higher overall richness. Notwithstanding, our results reinforced the importance of vegetation, humidity and temperature affecting the structure of sphingid assemblages in the Amazon region.

Our results revealed that species composition was strongly associated with the quality of the habitat. Areas with disturbed vegetation and close to cities, such as Beruri and Itacoatiara, have a similar diversity pattern when comparing assemblages using species composition. Additionally, considering species composition in disturbed and undisturbed areas, our results showed that minimum 
temperature and relative humidity are relevant environmental variables affecting hawkmoth composition. Among the areas with pristine vegetation, JNP and SGC were more similar and have higher relative humidity and minimum temperatures. In contrast, those with disturbed vegetation, Beruri and Itacoatiara, have lower relative humidity and minimum temperatures in comparison with the other sites. These differences may be related to the reduced vegetation cover in areas of pasture and cupuaçu plantations, which reduces the humidity, in turn producing greater temperature ranges (i.e., higher temperatures during the day and lower temperatures during the night). These abiotic differences were also shown to be important in a comparison of primary forest, logged forest, second-growth forest and pasture in the Eastern Amazon of Pará state (Uhl and Kauffman 1990).

These general differences in the composition and structure of the sphingid community between pristine and disturbed areas may be related to the differences in habitat occupancy among different sphingid subfamilies. While members of the subfamily Smerinthinae occur preferentially in pristine habitats, those of the Macroglossinae subfamily are more common in disturbed ones (Beck et al. 2006a).

Similarly to our results, Ferro and Melo (2011) showed that tiger moth (Erebidae) assemblages in lowland areas of Atlantic forest are similar in composition, and this was mostly associated with high temperatures and precipitation. For nocturnal and ectothermic organisms such as hawkmoths, temperature and atmospheric moisture are, indeed, important environmental factors that affect survival, development (e.g., Subramanyam and Hagstrum 1993; Liu et al. 2002), reproduction (e.g., Zhang et al. 2013) and flight patterns. For species abundances using the BrayCurtis index, we found a similar pattern, indicating that areas with similar maximum temperature also have similar assemblages. Additionally, we also found that relative humidity is an important environmental factor influencing species composition. Relative humidity is known to affect both survival and foraging behavior of the long-tongued hawkmoth Manduca sexta, for example (Contreras et al. 2013).

\section{Temporal activity pattern}

Temporal activity patterns of Amazonian sphingids showed distinct trends at different taxonomic levels. With regard to abundances, with the exception of the tribes Macroglossini and Dilophonotini, all other pairwise comparisons between tribes and subfamilies showed differences in temporal activity. For example, for the abundances at subfamily level, long-tongued moths of the subfamily Sphinginae had peak activity at 01:00 h, whereas the peak for short- tongued moths of subfamily Macroglossinae was at 05:00 h. Long-tongued hawkmoths are ecologically linked to highly specialized sphingophilous flowers (Johnson and Raguso 2016; Sazatornil et al. 2016), i.e., flowers with nocturnal anthesis, scent production and long corolla tubes (see Haber and Frankie 1989; Amorim et al. 2014), whereas short-tongued moths are more generalist and visit a wider group of flowers. Thus, such a pattern may also be related to differences in resource use by long- and shorttongued moths. However, we cannot rule out the influence of other important variables, such as larval hostplants, gender flight time differences or even phylogenetic covariation.

For the richness at each taxonomic level, we also found a pronounced difference in the peaks of sphingid occurrence through the night, especially at tribal level. Such differences may be related to resource competition and predation avoidance, as noted in a previous study (see Camargo et al. 2016). For this reason, species that are present in one period of the night are not necessarily present in another or less abundant. Therefore, our results highlight the importance of full night sampling efforts to better characterize sphingid diversity and community structure.

\section{Conclusions}

The Brazilian Amazon is a hyperdiverse tropical ecosystem and, due to its huge land area with distinct biotic and abiotic factors and difficulties in accessing the more remote areas, still lacks good characterization for most invertebrate groups, including globally well studied insects such as hawkmoths. According to our estimates, about 20 species still remain to be found in the Amazon, which alone is expected to harbor more than half of the hawkmoth diversity found in South America, and more than $80 \%$ of the Brazilian fauna. But, as we show here, the composition of hawkmoth communities depends on the quality of the habitat, which in turn affects local abiotic factors such as temperature and humidity, and so, consequently, the assemblage structure. Given that hawkmoths are long-distance flying insects and the sole pollinators of many highly specialized plants in tropical ecosystems (Amorim et al. 2014), the continued presence of undisturbed areas in Amazon will play an important role in the conservation and maintenance of the South America hawkmoth fauna, as well as the plants that rely on them for reproduction. Thus, in addition to providing the first overview of hawkmoth species composition and diversity patterns in the Brazilian Amazon, this study highlights the importance of PAs for the maintenance of key ecosystem processes such as pollination. 
Acknowledgments We are grateful to Mr. João S. de Oliveira and Mr. Sebastião D. da Silva for fieldwork assistance. We are also very grateful to two anonymous reviewers for their comments and valuable suggestions that greatly improved the manuscript and to Graham E. Wyatt for the final English reviewing. We thank NGI-Altamira/ ICMBio for the logistical support and COAPE/ICMBio for the project funding and Rafael Zenni for helping in statistical analysis. EMV thanks the Brazilian National Council for Scientific and Technological Development (Conselho Nacional de Desenvolvimento Científico e Tecnológico- $\mathrm{CNPq}$ ) for the Research Productivity Grant received (No. 308153/2007-3). FWA also thanks CNPq for financial support (Proc. No. 484469/2013-4).

\section{References}

Ab'Saber AN (1977) Os domínios morfoclimáticos na América do Sul: Primeira aproximação. Universidade de São Paulo, Instituto de Geografia, São Paulo

Amorim FW, de Ávila RS, de Camargo AJA, Vieira AL, Oliveira PE (2009) A hawkmoth crossroads? species richness, seasonality and biogeographical affinities of Sphingidae in a Brazilian Cerrado. J Biogeogr 36:662-674

Amorim FW, Wyatt GE, Sazima M (2014) Low abundance of longtongued pollinators leads to pollen limitation in four specialized hawkmoth-pollinated plants in the Atlantic Rain forest, Brazil. Naturwissenschaften 101:893-905

Axmacher JC, Brehm G, Hemp A, Tünte H, Lyaruu HV, MüllerHohenstein K, Fiedler K (2009) Determinants of diversity in Afrotropical herbivorous insects (Lepidoptera: Geometridae): plant diversity, vegetation structure or abiotic factors? J Biogeogr 36:337-349

Ballesteros-Mejia L, Kitching IJ, Beck J (2011) Projecting the potential invasion of the Pink Spotted Hawkmoth (Agrius cingulata) across Africa. Int J Pest Manag 57:153-159

Beck J, Kitching IJ, Linsenmair KE (2006a) Effects of habitat disturbance can be subtle yet significant: biodiversity of hawkmoth-assemblages (Lepidoptera: Sphingidae) in Southeast-Asia. Biodivers Conserv 15:465-486

Beck J, Kitching IJ, Linsenmair EK (2006b) Determinants of regional species richness: an empirical analysis of the number of hawkmoth species (Lepidoptera: Sphingidae) on the Malesian archipelago. J Biogeogr 33:694-706

Bolker BM (2008) Ecological models and data in R. Princeton University Press, Princeton

Brehm G, Fiedler K (2003) Faunal composition of geometrid moths changes with altitude in an Andean montane rain forest. J Biogeogr 30:431-440

Camargo AJA, Cavalcanti W (1999) Instruções para a confecção de armadilha luminosa para captura de insetos noturnos. Embrapa CPAC, Brasília

Camargo NF, Camargo WR, Corrêa DCV, Camargo AJA, Vieira EM (2016) Adult feeding moths (Sphingidae) differ from non-adult feeding ones (Saturniidae) in activity-timing overlap and temporal niche width. Oecologia 180:313-324

Chapman JW, Reynolds DR, Mouritsen H, Hill JK, Riley JR, Sivell D, Smith AD, Woiwod IP (2008) Wind selection and drift compensation optimize migratory pathways in a high-flying moth. Curr Biol 18:514-518

Colwell RK (2013) EstimateS: statistical estimation of species richness and shared species from samples: version 9.0. User's Guide and Application. http://purl.oclc.org/estimates. Accessed 20 July 2015

Colwell RK, Chao A, Gotelli NJ, Lin SY, Mao CX, Chazdon RL, Longino JT (2012) Models and estimators linking individual- based and sample-based rarefaction, extrapolation and comparison of assemblages. J Plant Ecol 5:3-21

Contreras HL, Goyret J, Von Arx M, Pierce CT, Bronstein JL, Raguso RA, Davidowitz G (2013) The effect of ambient humidity on the foraging behavior of the hawkmoth Manduca sexta. J Comp Physiol A 199:1053-1063

D'Abrera B (1986) Sphingidae Mundi: Hawk Moths of the World. E. W. Classey, Faringdon

Da Silva J, Cardos M, Rylands AB, Fonseca D, Gustavo A (2005) The fate of the Amazonian areas of endemism. Conserv Biol 19:689-694

Duarte M, Marconato G, Specht A, Casagrande MM (2012) Lepidoptera Linnaeus, 1758. In: Rafael JÁ, Melo GAR, Carvalho CJB, Casari AS, Constantino R (eds) Insetos do Brasil: Diversidade e taxonomia. Holos Editora, Ribeirão Preto, pp 625-682

Ferro VG, Melo AS (2011) Diversity of tiger moths in a neotropical hotspot: determinants of species composition and identification of biogeographic units. J Insect Conserv 15:643-651

Figueroa SN, Nobre CA (1990) Precipitations distribution over Central and Western Tropical South America. Bol Monit Anál Clim 5:36-45

Freitas BM, Pinheiro JN (2012) Polinizadores e pesticidas: princípios e manejo para os agroecossistemas brasileiros. MMA, Brasília

Google Inc (2015) Google Earth version 7.1.5.1557. https://www. google.com/earth/. Accessed 25 May 2016

Gotelli NJ, Chao A (2013) Measuring and estimating species richness, species diversity, and biotic similarity from sampling data. In: Levin SA (ed) Encyclopedia of biodiversity, vol 5, 2nd edn. Academic Press, Waltham, pp 195-211

Haber WA, Frankie GW (1989) A tropical hawkmoth community: costa Rican dry forest Sphingidae. Biotropica 21:155-172

Hammer Ø, Harper DAT, Ryan PD (2001) PAST: paleontological statistics. Software package for education and data analysis. Palaeontol Electron. http://palaeo-electronica.org/2001_1/past/ issue1_01.htm. Accessed 25 May 2016

Hawes J, Motta CS, Overal WL, Barlow J, Gardner TA, Peres CA (2009) Diversity and composition of Amazonian moths in primary, secondary and plantation forests. J Trop Ecol 25:281-300

Hernández LN, Barragán ÁR, Dupas S, Silvain JF, Dangles O (2010) Wing shape variations in an invasive moth are related to sexual dimorphism and altitude. Bull Entomol Res 100:529-541

Hilty J, Merenlender A (2000) Faunal indicator taxa selection for monitoring ecosystem health. Biol Conserv 92:185-197

Ignatov II, Janovec JP, Centeno P, Tobler MW, Grados J, Lamas G, Kitching IJ (2011) Patterns of richness, composition, and distribution of sphingid moths along an elevational gradient in the Andes-Amazon region of Southeastern Peru. Ann Entomol Soc Am 104:68-76

IMET (2015) National Institute of Meteorology. http://www.inmet. gov.br/projetos/rede/pesquisa/. Accessed on 25 May 2015

Johnson SD, Raguso RA (2016) The long-tongued hawkmoth pollinator niche for native and invasive plants in Africa. Ann Bot 117:25-36

Joppa LN, Roberts DL, Pimm SL (2011) How many species of flowering plants are there? Proc R Soc B: Biol Sci 278:554-559

Kawahara AY, Mignault AA, Regier JC, Kitching IJ, Mitter C (2009) Phylogeny and biogeography of hawkmoths (Lepidoptera: Sphingidae): evidence from five nuclear genes. PLoS One 4:e5719

Kitching IJ (2015) Sphingidae taxonomic inventory. http://sphingi dae.myspecies.info/. Accessed on 19 June 2015

Kitching IJ, Cadiou JM (2000) Hawkmoths of the world: an annotated and illustrated revisionary checklist (Lepidoptera: Sphingidae). Cornell University Press, Ithaca 
Landau D, Prowell D, Carlton CE (1999) Intensive versus long-term sampling to assess lepidopteran diversity in a southern mixed mesophytic forest. Ann Entomol Soc Am 92:435-441

Lange WH, Bronson L (1981) Insect pests of tomatoes. Ann Rev Entomol 26:345-371

Laurance WF, Cochrane MA, Bergen S, Fearnside PM, Delamônica P, Barber C, D'Angelo S, Fernandes T (2001) The future of the Brazilian Amazon. Science 5503:438-439

Liu SS, Chen FZ, Zalucki MP (2002) Development and survival of the diamondback moth (Lepidoptera: Plutellidae) at constant and alternating temperatures. Environ Entomol 31:221-231

Martins DJ, Johnson SD (2013) Interactions between hawkmoths and flowering plants in East Africa: polyphagy and evolutionary specialization in an ecological context. Biol J Linn Soc 110:199-213

Melo AS (2004) A critique of the use of jackknife and related nonparametric techniques to estimate species richness in assemblages. Community Ecol 5:149-157

Moré M, Kitching IJ, Cocucci AA (2005) Sphingidae: Esfíngidos de Argentina. LOLA, Buenos Aires

Moss AM (1920) Sphingidae of Pará, Brazil. Novit Zool 27:333-424

Motta CS, Andreazze R (2001) Esfingofauna (Lepidoptera, Sphingidae) do Parque Nacional do Jaú e arredores, Amazonas, Brasil. Acta Amazon 31:643-654

Motta CS, Andreazze R (2002) Sphingidae (Lepidoptera) de Querari, São Gabriel da Cachoeira, Amazonas, Brasil. Entomol Vect 9:329-337

Motta CS, Xavier-Filho FF (2005) Esfingídeos (Lepidoptera, Sphingidae) do município de Beruri, Amazonas, Brasil. Acta Amazon 35:457-462

Motta CDS, Ferreira RLM, Aguiar NO (1991) Sobre a esfingofauna da ilha de Maracá e da serra de Pacaraima, Roraima (Lepidoptera, Sphingidae). Acta Amaz 21:319-324

Motta CS, Aguilera-Peralta FJ, Andreazze R (1998) Aspectos da esfingofauna (Lepidoptera, Sphingidae), em área de terra firme no estado do Amazonas, Brasil. Acta Amaz 28:75-92

Nepstad DC, Stickler CM, Filho BS, Merry F (2008) Interactions among Amazon land use, forests and climate: prospects for a near-term forest tipping point. Philos Trans R Soc Lond B Biol Sci 363:1737-1746

Nieukerken EJV, Kaila L, Kitching IJ et al (2011) Order Lepidoptera Linnaeus, 1758. Zootaxa 3148:212-221

Nilsson LA, Jonsson L, Rason L, Randrianjohany E (1985) Monophily and pollination mechanisms in Angraecum arachnites Schltr. (Orchidaceae) in a guild of long-tongued hawkmoths (Sphingidae) in Madagascar. Biol J Linn Soc 26:1-19

Nunes AP, Ayres JM, Martins ES, Silva JS (1988) Primates of Roraima (Brazil): northeastern part of the territory. Bol Mus Para Emílio Goeldi (Ser Zool) 4:87-100

Oksanen J, Blanchet FG, Kindt R, Legendre P, Minchin PR, O'Hara RB, Simpson GL, Solymos P, Stevens MHH, Wagner H (2015) vegan: community ecology package. $\mathrm{R}$ package version 2.3-0. http://vegan.r-forge.r-project.org. Accessed 20 July 2015
Pinheiro F, Diniz IR, Coelho D, Bandeira MPS (2002) Seasonal pattern of insect abundance in the Brazilian cerrado. Austral Ecol 27:132-136

R Development Core Team (2014) R: a language and environment for statistical computing. $\mathrm{R}$ foundation for statistical computing. http://www.R-project.org. Accessed 20 July 2015

Ramos RM, Pezzuti JCB, Vieira EM (2014) Age structure of the vulnerable white-lipped peccary Tayassu pecari in areas under different levels of hunting pressure in the Amazon Forest. Oryx 48:1-7

Ratter JA, Bridgewater S, Ribeiro JF (2003) Analysis of the floristic composition of the Brazilian cerrado vegetation III: comparison of the woody vegetation of 376 areas. Edinb J Bot 60:57-109

Rothschild LW, Jordan K (1910) List of the Sphingidae collected by the late W. Hoffmanns at Allianca, Rio Madeira, Amazonas. Novit Zool 17:447-455

Salati E, Dos Santos ÂA, Klabin I (2006) Temas ambientais relevantes. Estud Av 20:107-127

Sazatornil F, Moré M, Benitez-Vieyra S, Cocucci AA, Kitching IJ, Schlumpberger BO, Oliveira PE, Sazima M, Amorim FW (2016) Beyond neutral and forbidden links: morphological matches and the assembly of mutualistic hawkmoth-plant networks. J Anim Ecol. doi:10.1111/1365-2656.12509

Skole D, Chomentowski WH, Salas WA, Nobre AD (1994) Physical and human dimensions of deforestation in Amazonia. BioScience 44:314-322

Steen R (2012) Pollination of Platanthera chlorantha (Orchidaceae): new video registration of a hawkmoth (Sphingidae). Nordic $J$ Bot 30:623-626

Subramanyam B, Hagstrum DW (1993) Predicting development times of six stored-product moth species (Lepidoptera: Pyralidae) in relation to temperature, relative humidity, and diet. Eur $\mathrm{J}$ Entomol 90:51-64

Tanzubil PB (2015) Insect pests of sweet potato in the Sudan savanna zone of Ghana. J Entomol Zool Stud 3:124-126

Uhl C, Kauffman JB (1990) Deforestation, fire susceptibility, and potential tree responses to fire in the eastern Amazon. Ecology 71:437-449

Vanhove MPM, Jocque M, Mann DJ, Waters S, Creedy TJ, NuñezMiño JM, Samayoa AC, Vaglia T, Casteels J (2012) Small sample, substantial contribution: additions to the Honduran hawkmoth (Lepidoptera: Sphingidae) fauna based on collections from a mountainous protected area (Cusuco National Park). J Insect Conserv 16:629-633

Wickham H, Chang W (2015) ggplot2: an implementation of the grammar of graphics. R package version 1.0.1. http://ggplot2. org. Accessed 20 July 2015

Xiong YZ, Liu CQ, Huang SQ (2015) Mast fruiting in a hawkmothpollinated orchid Habenaria glaucifolia: an 8-year survey. J Plant Ecol 8:136-141

Zhang W, Zhao F, Hoffmann AA, Ma CS (2013) A single hot event that does not affect survival but decreases reproduction in the diamondback moth, Plutella xylostella. PloS One 8:e75923 